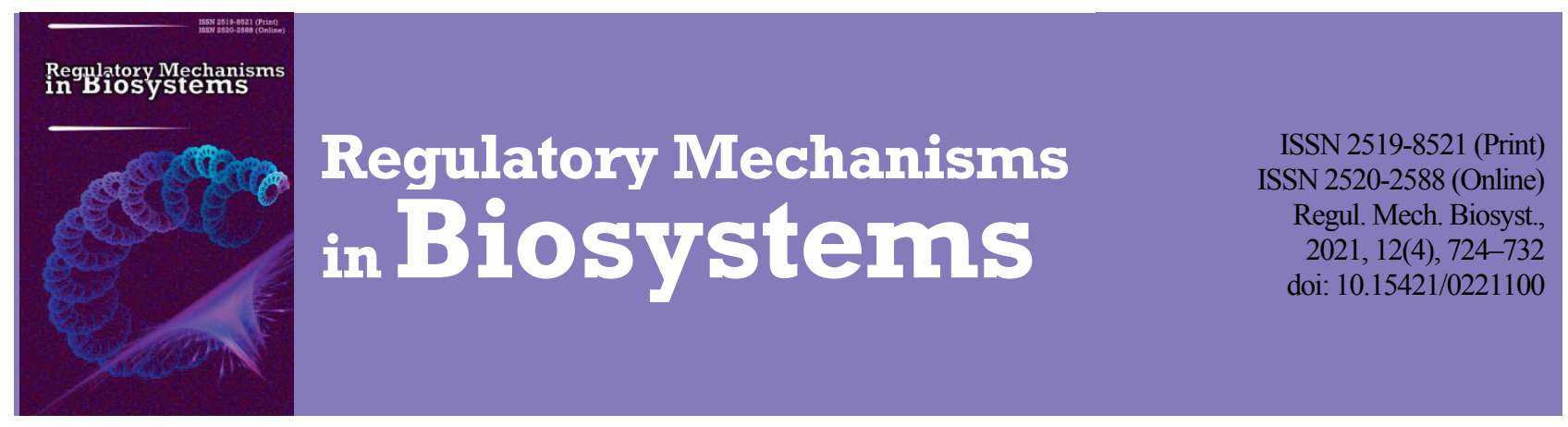

\title{
Comparative analysis of two methodological approaches to the study of endocrine disruptor alpha-cypermethrin reproductive toxicity
}

\author{
N. R. Shepelska, M. G. Prodanchuk, Y. V. Kolianchuk
}

\section{I. Medved's Research Center of Preventive Toxicology, Food and Chemical Safety, Kyiv, Ukraine}

Article info

Received 10.10.2021

Received in revised form

08.11 .2021

Accepted 09.11.2021

L. I. Medved's Research Center of Preventive

Toxicology, Food and

Chemical Safety,

Heroiv Oboronyst., 6

Kyiv, 03127, Ukraine.

Tel.: +38-063-067-68-78

E-mail: kolyanchukyana

(a) gmail.com

\begin{abstract}
Shepelska, N. R., Prodanchuk, M. G., \& Kolianchuk, Y. V. (2021). Comparative analysis of two methodological approaches to the study of endocrine disruptor alpha-cypermethrin reproductive toxicity. Regulatory Mechanisms in Biosystems, 12(4), 724-732. doi:10.15421/0221100
\end{abstract}

At present, one of the main threats to humanity is undoubtedly endocrine disruptors (ED), since they directly disrupt the processes of ensuring homeostasis, which are identical to the very essence of the concept of health, considered in valeology as the ability to maintain ageappropriate stability in conditions of sharp changes in quantitative and qualitative parameters of the triune flow of sensory, verbal and structural information. Pesticides can disrupt the physiological functioning of many endocrine chains, including the endocrine mechanisms that ensure reproductive health. The study aimed to compare the results of our studies of alpha-cypermethrin reproductive toxicity in the test system for studying gonadotoxic activity with data obtained in the test system "Three Generation Reproduction Study". The studies were performed on male and female Wistar Han rats with two generic samples of alpha-cypermethrin from different manufacturers at doses of $0.2,1.0$ and $3.0 \mathrm{mg} / \mathrm{kg}$ body weight. The exposure lasted 11 (males) and 10 (females) weeks. During the last two weeks of exposure the state of the estrous cycle, duration and frequency of each stage in females was studied. After the end of treatment functional parameters of the state of the gonads in males and the ability of animals to reproduce were examined. In males, the total sperm count, the absolute and relative number of motile germ cells, and the number of pathologically altered forms were evaluated. The results of the study showed that exposure of male and female Wistar Han rats to alpha-cypermethrin at doses of $0.2-3.0 \mathrm{mg} / \mathrm{kg}$ during gametogenesis had a toxic effect on the reproductive system characterized by impaired gonadal and reproductive functions. In our studies, alpha-cypermethrin was found to have reproductive toxicity (reduced number of corpora luteum and live fetuses, increased absolute and relative postimplantation death, reduced average weight of fetuses and litters) and endocrine-disruptive effect, having a pronounced antiandrogenic effect on males. Obvious signs of endocrine reproductive disorders (changes in testis and epididymis weight, deterioration in semen parameters, altered length of separate stages of the estrous cycle) were observed in both females and males. However, studies in a test system of three-generations did not reveal a reproductive and endocrine-disruptive effect of cypermethrin, the toxicity of which was recognized as equivalent to the toxicity of alphacypermethrin. The obtained results showed higher sensitivity, informative and diagnostic significance of the methods for studying gonadotoxicity than the methodology of reproductive toxicity studies in the test system "Three Generation Reproduction Study".

Keywords: test system for studying gonadotoxic activity; three generation reproduction study; antiandrogenic activity; estrogen-like effects; study on rats; in vitro.

\section{Introduction}

At present, one of the main threats to humanity is undoubtedly endocrine disruptors (ED), since they directly disrupt the processes of ensuring homeostasis, which are identical to the very essence of the concept of health, considered in valeology as "the ability to maintain age-appropriate stability in conditions of sharp changes in quantitative and qualitative parameters of the triune flow of sensory, verbal and structural information" (Brekhman, 1990). Pesticides can disrupt the physiological functioning of many endocrine chains, including the endocrine mechanisms that ensure reproductive health. It should be noted that research aimed at preventing chemically induced reproductive disorders in the human population is one of the central areas of preventive medicine, both in terms of its importance and the complexity of the tasks being solved.

An understanding of the need to develop methodological approaches to examine possible violations of reproductive function under the influence of xenobiotics entering the human body through food, water, air throughout life, developed in the 1950s. As a result of long discussions (Barnes \& Denz, 1954; Lehman, 1958) and debates, the methodological test "Three Generation Reproduction Study" was proposed (Lenz, 1958; Fitzhugh, 1968; Fishbein, 1970). According to the proposed experimental scheme, testing of chemical compounds provided for the study of reproductive function of at least three generations and 9 litters ( 3 litters in each generation). Despite the fact that for a long time this methodological approach was used by all the leading scientific centers of the world, the problem of optimizing the experimental design remained the subject of extensive scientific discussion (Delahunt \& Lassen, 1964; Palmer, 1978; Palmer, 1981), which eventually led to a significant revision of the original experimental design.

Since 1982 the initial methodological approach for assessing the risk of xenobiotics' reproductive toxicity, in particular, plant protection chemicals, has been transformed into the most widely used test system "TwoGeneration Reproduction Toxicity Study", which involves the study of two generations and one litter in each generation of animals.

In test systems of the 2nd and 3rd generations, the research focuses on the assessment of qualitative and quantitative indicators that characterize the ability to reproduce in parental animals, that is, fertility, as well as the processes of offspring development. Along with the above tests, considerable attention is paid to histomorphological studies of the tissues of the internal organs of adult animals and offspring.

It should be emphasized that the processes of gonad functioning have not been evaluated for a long time. Only towards the end of the 1990s was 
it understood that in the test system of several generations of animals, the most important parameters of the reproductive system state were overlooked by researchers. Namely: direct indicators of the gonad functioning.

In 1996, a group of experts published an article (Seed et al., 1996) that began with the words: "Until recently, the ability of compounds to induce damage to the male reproductive system was evaluated based on fertility studies in an experiment on rats or mice. However, it has now been found that fertility in rodents is not the most sensitive and reliable indicator of possible impairment'. The authors of the article recognized the need to review the research protocol in order to include in it the assessment of quantitative and qualitative sperm parameters. Revision was carried out in 1998. That is, before that, reproductive toxicity was assessed without using the most sensitive and reliable indicators.

Thus, the optimization of pesticides reproductive toxicity study in the test system of several generations of animals was reduced to a gradual reduction in the number of generations and litters, and the necessity to estimate the state of the gonads. This trend continues nowadays. But, despite the significant improvement in the protocols of these studies, the need for their further rationalization remains pressing. Thus, one of the disadvantages of the listed approaches is the impossibility of identifying the target organ and sexual selectivity for the effect of the tested compounds, since both females and males are exposed simultaneously. Therefore, if it is necessary to establish the mechanism of toxic action in a number of cases, additional experiments are required in which cross-mating of treated animals with untreated (intact) females and males is carried out.

A somewhat different approach to the study of reproductive toxicity of pesticides has been adopted in our country. The first guidelines for the study of reproductive toxicity of pesticides were published in 1969. These included studies of the gonadotoxic activity of pesticides and studies of the developmental effects of these xenobiotics. A second revised edition was published in 1988. As the gonads, accessory reproductive glands and neuroendocrine system are extremely sensitive to the toxic effects of chemicals, and there are sex-related differences in sensitivity to toxic factors, the primary focus was on studying the gonadotoxic activity of chemical compounds and resulting potential reproductive dysfunction in treated male and female animals.

When studying the gonadotoxic effect, females and males of experimental animals are induced to mate, which then mate with intact females and males. The effect of the studied agent on embryogenesis is excluded in this experiment. Disorders of offspring development or reproductive function found in the course of these studies are clearly associated with the effect on the gonads and other reproductive organs. Planning the experiment involves obtaining information on gonadal function, sexual beha- viour of animals, their ability to mate, conception, fertilization and fertility. The parameters of prenatal development of $F_{1}$ generation are determined as well.

Changes here can be manifested by a slowdown or cessation of the production of germ cells, the formation of defective cells with reduced fertility or fertilizing ability, the production of cells that carry hereditary changes in their genetic apparatus or a violation of the ability to normal development of a fertilized egg.

It is necessary to take into account that the toxic effect on various links of the reproduction process can be carried out directly by exposure of the gonads and other reproductive organs or as a result of the influence on the hypothalamus-pituitary-gonad system. All these effects are assessed both with the help of special morpho-functional tests, morphometric parameters of the state of the gonads, histological evaluation and by studying the results of the $F_{1}$ offspring reproduction. It should be emphasized here that at present, when assessing the danger of reproductive toxicity of pesticides, the protocol of mandatory studies in the test system of two generations of animals also includes the study of some parameters of sperm in males and sexual cycles in females. However, in our opinion, the diagnostic potential of such a valuable indicator of the reproductive system in females as the state of the estrous cycle is far from being fully utilized. In foreign studies of the reproductive toxicity of pesticides, only the cycle duration and their amount are presented. Thus, separate phases of the cycle, their duration and regularity are not investigated.

But changes in hormonal status of females, accompanied by a violation of the regularity and alternation of sexual cycle phases, regardless of their mechanism of origin, are characterized by an imbalance of estrogens and progesterone. The genetic similarity of the structure of estrous cycles in rodents and menstrual cycles in primates (including humans) is due to the lack of species specificity of hormones. This makes it possible to use such a simple and accessible method for identifying endocrine disruptors and to extrapolate to humans the data obtained in experiments on female rodents. This paper is a fragment of long-term research devoted to the study of reproductive toxicity of 156 samples of 20 different pesticides under conditions affecting the gonads of male and female rats during gametogenesis and a comparative evaluation of the results obtained and the results of studying these pesticides in the test systems "Two-Generation Reproduction Toxicity Study" and "Three Generation Reproduction Study" (Table 1). For a comparative evaluation of diagnostic value and sensitivity of the approaches under consideration, we have presented the results of our study of the gonadotoxic activity of two samples of alphacypermethrin ( $\mathrm{ACl}$ and $\mathrm{AC} 2)$ and the results of study of reproductive toxicity of this xenobiotic in "Three Generation Reproduction Study".

Table 1

List of generic pesticides researched in the test system for studying gonadotoxic activity

\begin{tabular}{|c|c|c|c|}
\hline Name of active ingredient & $\begin{array}{l}\text { Number of generic } \\
\text { samples studied }\end{array}$ & $\begin{array}{l}\text { NOAEL*, } \mathrm{mg} / \mathrm{kg} \\
\text { body weight bw }\end{array}$ & Generalized results of the study of generic samples of each pesticide \\
\hline Carbendazim $(\mathrm{C})$ & 20 & 2.5 & \multirow{7}{*}{$\begin{array}{l}\text { Antiandrogenic effect - impaired spermatogenesis }(\mathrm{C}, \mathrm{I}, \mathrm{P}, \mathrm{B}, \mathrm{F}, \mathrm{Ch}, \mathrm{ChCh}) \text {, decreased in testes } \\
\text { and epididymis weight }(\mathrm{P}, \mathrm{B}, \mathrm{F}, \mathrm{Ch}) \text {, hypotrophy of the testes and epididymis, azoospermia }(\mathrm{C}) \text {, } \\
\text { increased intrauterine death of offspring }(\mathrm{C}, \mathrm{I}, \mathrm{P}, \mathrm{F}) \text {, decreased pregnancy indexes }(\mathrm{P}) \text {, decreased } \\
\text { litter size }(\mathrm{F}) \text { in intact females when exposed to } \mathrm{O} \text {. }\end{array}$} \\
\hline Imazalil (I) & 2 & 0.5 & \\
\hline Pyrimiphos-methyl (P) & 2 & 0.3 & \\
\hline Bentazone (B) & 11 & 1.0 & \\
\hline Flurochloridone $(\mathrm{F})$ & 1 & 0.9 & \\
\hline Chlorimuron-ethyl(Ch) & 2 & 0.01 for $\widehat{\partial} \widehat{\partial}$ & \\
\hline Chlormequat chloride (ChCh) & 3 & 5.0 for $\stackrel{\AA}{\partial}$ & \\
\hline Tebuconazole(TB) & 1 & 5.0 & \multirow{7}{*}{ 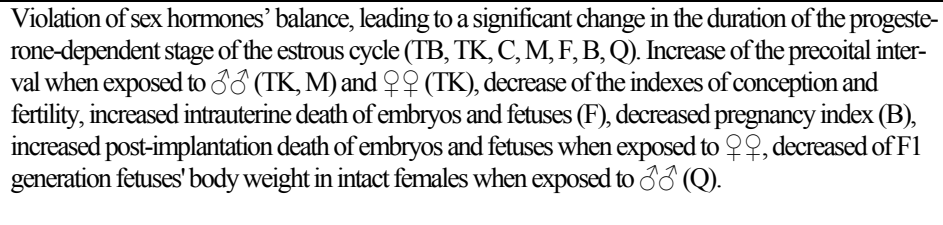 } \\
\hline Tetraconazole (TK) & 1 & 0.5 & \\
\hline Carboxin $(\mathrm{C})$ & 5 & 1.0 & \\
\hline Mancozeb (M) & 8 & 5.0 & \\
\hline Flutriafol (F) & 17 & 1.0 & \\
\hline Benomil (B) & 1 & 2.0 & \\
\hline Quizalofop-p-ethyl (Q) & 1 & 0.2 & \\
\hline Cyproconazole (C) & 12 & 0.2 & \multirow{8}{*}{ 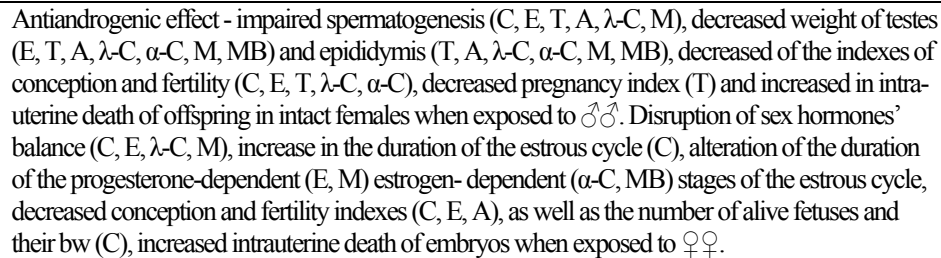 } \\
\hline Epoxiconazole(E) & 5 & 0.5 & \\
\hline Thiabendazole (T) & 7 & 10.0 & \\
\hline Azoxystrobin (A) & 14 & 6.0 & \\
\hline$\alpha$-cypermethrin $(\alpha-C)$ & 15 & 0.2 & \\
\hline Lambda-cyhalothrin $(\lambda-\mathrm{C})$ & 18 & 0.3 & \\
\hline Metolachlor (M) & 5 & 5.0 & \\
\hline Metribuzin (MB) & 5 & $<0.4$ for $\hat{\partial} \bar{\partial}, 1.5$ for & \\
\hline
\end{tabular}

Note: *-NOAEL-no-observed-adverse-effect-level. 


\section{Materials and methods}

Our research on the animals was conducted in accordance with the requirements and provisions of the European Convention for the Protection of Vertebrate Animals Used for Scientific Experiments or Other Scientific Purposes of 1986, and complied with the ARRIVE guide-lines and recommendations for using animals in scientific purposes (Kilkenny et al., 2010). The studies were carried out using two generic samples of alpha-cypermethrin technical ( $\mathrm{AC} 1$ and $\mathrm{AC} 2)$ from different manufacturers (purity $-95.0 \%$ and $97.1 \%$, respectively).

Cypermethrin - (R, S)-a-cyano-3-phenoxybenzyl (1RS)-cis-trans-3(2,2-dichlorovinyl)-2,2-dimethylcyclopropanecarboxylate belongs to the second generation pyrethroids. This compound is currently a widely used insecticide (mainly for agriculture) in the world.

The cypermethrin molecule contains 3 asymmetric carbon atoms, that is, $2^{3}=8$ isomers are possible for it (Fig. 1). Each of these isomers, to one degree or another, exhibits insectoacaricidal properties - one of the isomers is more active against Lepidoptera, the other against Coleoptera, etc. Thus, the activity of commercial cypermethrin, as well as the specificity of this activity, strongly depends on its isomeric composition, and therefore, on the world market, various isomeric mixtures of cypermethrin are labeled differently.<smiles>CC1(C)[C@H](C=C(Cl)Cl)[C@@H]1C(=O)O[C@H](C#N)c1cccc(Oc2ccccc2)c1</smiles>

Fig. 1. Asymmetric centers in the cypermethrin molecule

Cypermethrin is a racemic mixture of cis- and trans-isomers of cypermethrin, their ratio roughly ranges from 40:60 to 50:50. Alpha-cypermethrin is a racemic mixture containing only cis-isomers of cypermethrin mainly (1R-cis)S and (1S-cis)R-isomers (Mel'nikov, 1995).

Male and female Wistar Han rats between the ages of 5-6 weeks weighing $80-100 \mathrm{~g}$ that were obtained from SPF breeding nursery of L. I. Medved's Research Center of Toxicology MH Ukraine were used for the experiments. The adaptation period lasted for five days. The animals were housed in a room with a forced ventilation (12 air changes per hour) at a temperature and relative air humidity of $19-24^{\circ} \mathrm{C}$, humidity of 30-70\%. A 12-hour light/12-hour dark cycle was used. The animals received both deionized drinking water disinfected with UV light and purified through a reverse osmosis system and balanced granulated hypophytoestrogenic food (Altromin, Germany) ad libitum.

To study the gonadotoxic activity of $\mathrm{AC} 1$, four groups of animals ( 25 males and 25 females per group) were administered $\mathrm{AC} 1$ at a dose of 0.0, $0.2,1.0$ and $3.0 \mathrm{mg} / \mathrm{kg}$, respectively, for 11 (males) and 10 (females) weeks. To study the gonadotoxic activity of $\mathrm{AC} 2$, three groups of male rats (20 animals per group) were administered $\mathrm{AC} 2$ at a dose of $0.0,0.2$, and $2.0 \mathrm{mg} / \mathrm{kg}$, respectively, for 11 weeks. The test substances were administered by gavage in the form of an aqueous emulsion daily, 5 days a week. Control animals received distilled water with an emulsifier (OP-10) in equivalent amounts. Along with control animals and treated animals, intact males and females (untreated) were kept intended for mating ( $\mathrm{ACl}$ 40 males and 75 females; AC2 -60 females, Table 2). The male rats were weighed weekly during the entire exposure period, and the female rats were weighed (scales - KERN EG 4200-2NM) weekly until the mating period and on the 0th, 6th, 13th, and 20th days post coitum.

During the last two weeks of the exposure period, the state of the estrous cycle, its length and frequency of each its stage in female animals were studied. Since the state of the mucous membrane of the uterus and vagina synchronously reacts to the functioning of the ovaries and processes associated with the rhythmic maturation of follicles, ovulation and the formation of corpora luteum, the composition of cells in a vaginal smear reflects the functional state of the ovaries, as well as the balance of steroids and gonadotropins (Goldman, 2007). The average duration of the estrous cycle in rats is 4-5 days. In toxicological studies, data presented with characteristics of the oestrous cycle, are helpful for various reasons.

As noted earlier, changes in endocrine connections between the hypothalamus, pituitary, and ovaries as components of the reproductive axis can markedly affect cycling. Toxic effects on any of these links can disrupt the cycle and block ovulation. In addition, the regularity of cycle changes can often provide valuable information about the nature of the compound effects on the reproductive system. Disruption of the cycle caused by xenobiotics can induce acyclicity, changes in the duration of the individual stages of the oestrous cycle and cause an irregular cycle of abnormal duration (Bretveld, 2006).

\section{Table 2}

Number of animals in groups, dose regimen and duration of exposure

\begin{tabular}{|c|c|c|c|c|}
\hline $\begin{array}{c}\text { Active } \\
\text { substance }\end{array}$ & Groups & $\begin{array}{c}\text { Number of } \\
\text { animals (sex) }\end{array}$ & $\begin{array}{l}\text { Doses, } \\
\mathrm{mg} / \mathrm{kg}\end{array}$ & $\begin{array}{c}\text { Exposure period, } \\
\text { weeks }\end{array}$ \\
\hline \multirow{5}{*}{$\mathrm{AC} 1$} & I & $25($ ○) $), 25(+)$ & 0.0 & $11 / 9$ \\
\hline & II & $25(\overbrace{}^{\pi}), 25(+)$ & 0.2 & $11 / 9$ \\
\hline & III & $25(\overbrace{}^{\pi}), 25(+)$ & 1.0 & $11 / 9$ \\
\hline & IV & $25(0), 25$ (†) & 3.0 & $11 / 9$ \\
\hline & Intact & $40\left(0^{\top}\right), 75(+)$ & - & - \\
\hline \multirow{4}{*}{$\mathrm{AC} 2$} & I & $20 \hat{\sigma}$ & 0.0 & 11 \\
\hline & II & $20 \hat{\jmath}$ & 0.2 & 11 \\
\hline & III & $20 \widehat{\jmath}$ & 2.0 & 11 \\
\hline & Intact & 60 우 & - & - \\
\hline
\end{tabular}

Note: "-"- animals without treatment.

After completion of the exposure period, the parameters of the gonads' functional state and reproductive capacity of males and females were studied. Male fertility depends on the continuous daily production of millions of sperm. The process of spermatogenesis is highly complex, including a coordinated series of mitotic and meiotic divisions, improved cytodifferentiated stages, and constantly changing intercellular interactions, controlled by the autocrine, paracrine and endocrine systems. All these processes of spermatogenesis in male rats last 70 days, which was the reason for mode of action of the test compounds. The parameters assessed in our studies (such as the total number of spermatozoa, the number and percentage of motile spermatozoa and their pathological forms) indicate the quality of the spermatogenesis process (development, maturation, etc.) (Seed et al., 1996).

To study the morpho-functional state of the testes, and the weight of the testes and epididymis, animals were euthanized in a $\mathrm{CO}_{2}$ box. The abdominal cavity was opened, the right testes taken, the epididymis removed, carefully freed from adipose tissue and weighed (scales AXIS-AD300). Laboratory tubes were preliminarily prepared with $2 \mathrm{~mL}$ of physiological solution in each, which were labeled in accordance with the numbers of the tested males and placed in a water thermostat at $37^{\circ} \mathrm{C}$. After that, about $0.5 \mathrm{~mL}$ of physiological solution from a corresponding test tube was poured onto a watch glass heated in a microthermostat (Microthermostat Termo Blok), the epididymis put in it, cut lengthwise, after which the physiological solution, together with the dissected epididymus, was returned to the same test tube. The contents of the tube were vigorously shaken and immersed in a water thermostat. After that, the resulting suspension of spermatozoa with leukocyte melanger was taken up to the first mark and diluted with physiological solution (temperature $37^{\circ} \mathrm{C}$ ) to the second mark, the melanger (hemocytometer - model 851) was shaken, lowered two drops, and the resulting suspension was filled in a Goryaev chamber (model 851, MRTU 64-1-816-63) for counting blood cells heated to $37^{\circ} \mathrm{C}$. The number of total sperm, motile sperm, and abnormal sperm were counted using a light microscope (microscope Axioscop 40 CarlZeiss, $\times 200$ ).

Exposed and intact animals were mated to study the reproductive function. The state of reproductive function was considered on the 20th day of pregnancy in treated females which became pregnant by mating with intact males and intact females mated with treated males. The number of corpora lutea in the ovaries, the number of live, dead, and resorbed fetuses and embryos, fetal weight, total litter weight, and the presence of gross congenital malformations were recorded. The indexes of mating, fertility and pregnancy were determined by the following formulae:

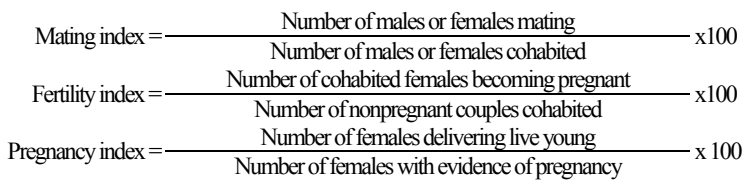


Precoital interval was determined as the time elapsed from males being presented to females to the confirmation of fertilization. The value of the precoital interval is calculated by the formula:

$$
\frac{\sum(\mathrm{A} \cdot \mathrm{B})}{\mathrm{C}}
$$

A - day of mating period, $\mathrm{B}$ - number of females mated on this day, $\Sigma-$ $\operatorname{sum}(\mathrm{A} \cdot \mathrm{B})$ for all mating days, $\mathrm{C}$ - the total number of mating females.

All data obtained experimentally were processed statistically using the computer program Prizm 6. The results were determined as mean \pm standard error $(\mathrm{x} \pm \mathrm{SE})$. Differences between the groups were determined using the Tukey test, where the differences were considered probable at $\mathrm{P}<0.05$, Bonferroni correction was taken into account.
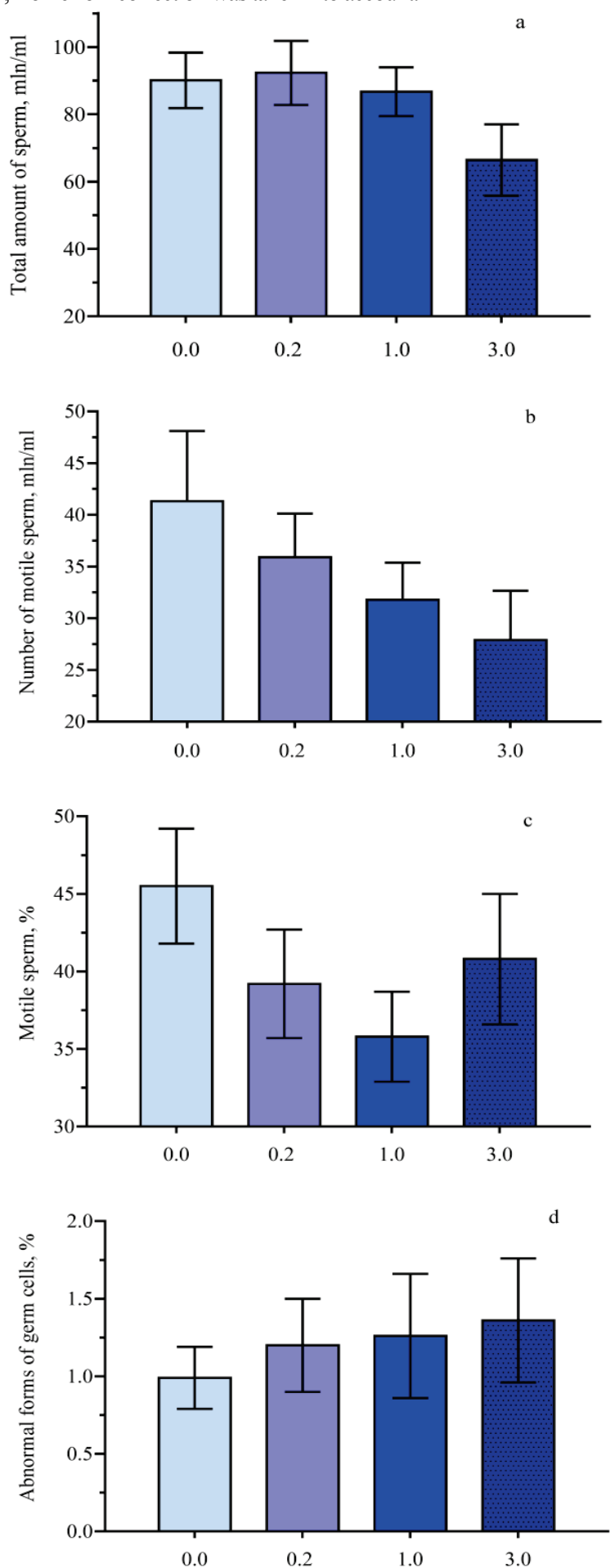

Fig. 2. Morpho-functional parameters of male sperm after exposure to alpha-cypermethrin (AC)

$\mathrm{n}=10 ; \mathrm{x} \pm \mathrm{SE}$; differences between the mean values were calculated using the Bonferroni-corrected ANOVA criterion, considered to be significant at * $-\mathrm{P}<0.05 ; * *-\mathrm{P}<0.01 ; * * *-\mathrm{P}<0.001$ compared to control group; 0.0, 0.2, 1.0, 2.0 and 3.0 - doses of alpha-cypermethrin (mg/kg); $a, b, c, d$-group of animals treated by $\mathrm{AC} 1 ; e, f, g, h$-group of animals treated by $\mathrm{AC} 2$ 

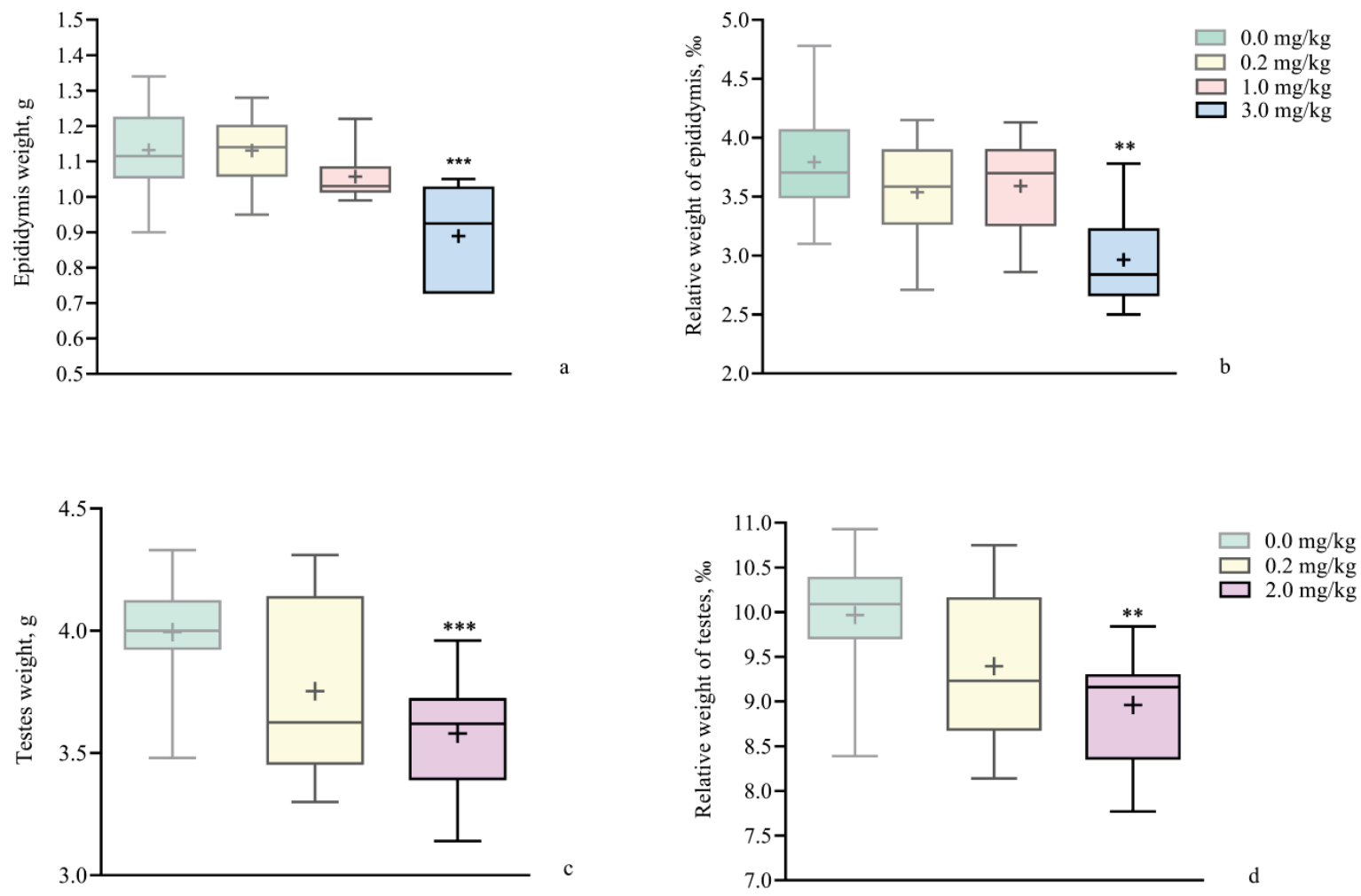

Fig. 3. Morphometric parameters of the testes and epididymis of males after exposure to alpha-cypermethrin (AC):

$\mathrm{n}=10 ; \mathrm{x} \pm \mathrm{SE} ;$ " + " - in boxplot indicate the mean; line in boxplot indicate the median; differences between the mean values were calculated using the Bonferroni-corrected ANOVA criterion, considered to be significant at ${ }^{*}-\mathrm{P}<0.05$; $* *-\mathrm{P}<0.01$; *** $-\mathrm{P}<0.001$ compared to control group; $a, b$ - group of animals treated by $\mathrm{AC} 1 ; c, d$ - group of animals treated by $\mathrm{AC} 2$

Macroscopic examination of the testes and epididymis did not reveal any visual pathology of these organs. However, according to Figure 2, statistically significant deviations were observed in sperm parameters upon exposure to $\mathrm{AC} 2$ at a dose of $2.0 \mathrm{mg} / \mathrm{kg}$, which were characterized by a decline in the total sperm count and the absolute and relative number of motile sperm as compared to those in the control group $(13.0 \%, 27.5 \%$ and $16.7 \%$, respectively). In this group of male animals, a significant increase in the percentage of abnormal sperm ( $117.1 \%$ above control) was observed as well. In males receiving $\mathrm{AC} 1$ at a dose of $3.0 \mathrm{mg} / \mathrm{kg}$, there was a tendency to a decline in the total sperm count and the number of motile sperm ( $26.3 \%$ and $32.4 \%$, respectively, below control); however, due to the significant individual variability of these parameters in the gro- ups, the mean values did not reach the significance level. A sample of $\mathrm{AC} 1$ compound under study induced a statistically significant reduction in the absolute and relative weight of the epididymis in animals receiving the maximum dose of $3.0 \mathrm{mg} / \mathrm{kg}(21.4 \%$ and $22.1 \%$, respectively, below control), while exposure to $\mathrm{AC} 2$ at a dose of $2.0 \mathrm{mg} / \mathrm{kg}$ resulted in a statistically significant reduction in the absolute and relative weight of the testes ( $10.2 \%$ and $10.1 \%$, respectively, below control, Fig. 3 ).

The fertilizing ability of treated males and their fertility, which were evaluated by the indices of mating and fertility of intact females, tended towards decrease in the indices of fertility ( $\mathrm{ACl}$ and $\mathrm{AC} 2)$ as compared to the control group, demonstrating non-monotonic dose dependence (AC1) (Table 3).

Table 3

State of reproductive function $(\%, \mathrm{x} \pm \mathrm{SE}, \mathrm{n}=25)$ in treated females and intact females mated with males receiving alpha-cypermethrin

\begin{tabular}{lc|ccc|ccc}
\hline \multicolumn{1}{c}{ Parameters } & Control group & \multicolumn{3}{c|}{ Treated females } & \multicolumn{3}{c}{ Intact females } \\
\cline { 2 - 7 } & $0.0 \mathrm{mg} / \mathrm{kg}$ & $0.2 \mathrm{mg} / \mathrm{kg}$ & $1.0 \mathrm{mg} / \mathrm{kg}$ & $3.0 \mathrm{mg} / \mathrm{kg}$ & $0.2 \mathrm{mg} / \mathrm{kg}$ & $1.0 \mathrm{mg} / \mathrm{kg}$ & $3.0 \mathrm{mg} / \mathrm{kg}$ \\
\hline Index of mating, \% & 96 & 100 & 100 & 100 & 96 & 100 & 100 \\
Index of fertility, \% & 96 & 92 & 92 & 100 & 92 & 100 & 88 \\
Index of pregnancy, \% & 100 & 100 & 100 & 100 & 100 & 100 & 100 \\
Number of corpora lutea & $13.38 \pm 0.48^{\mathrm{a}}$ & $12.39 \pm 0.55$ & $12.13 \pm 0.39^{\mathrm{a}}$ & $12.00 \pm 0.47^{\mathrm{a}}$ & $13.22 \pm 0.39$ & $13.64 \pm 0.42$ & $12.90 \pm 0.40$ \\
Number of live fetuses & $11.54 \pm 0.27^{\mathrm{a}}$ & $10.65 \pm 0.55$ & $10.30 \pm 0.50^{\mathrm{a}}$ & $9.92 \pm 0.73^{\mathrm{a}}$ & $10.61 \pm 0.77$ & $10.96 \pm 0.57$ & $9.82 \pm 0.70^{\mathrm{a}}$ \\
Number of embryo pre-implantation deaths & $1.42 \pm 0.27$ & $1.09 \pm 0.28$ & $1.26 \pm 0.22$ & $1.44 \pm 0.62$ & $1.87 \pm 0.66$ & $1.28 \pm 0.42$ & $1.64 \pm 0.50$ \\
Pre-implantation mortality, \% & $10.29 \pm 1.64$ & $8.51 \pm 2.51$ & $9.93 \pm 1.51$ & $12.90 \pm 4.16$ & $13.82 \pm 4.42$ & $8.90 \pm 2.60$ & $13.39 \pm 3.80$ \\
Number of embryo and fetal post- & $0.42 \pm 0.10^{\mathrm{a}}$ & $0.65 \pm 0.22$ & $0.57 \pm 0.17$ & $0.56 \pm 0.10$ & $0.74 \pm 0.17$ & $1.40 \pm 0.47^{\mathrm{a}}$ & $1.14 \pm 0.23^{\mathrm{a}}$ \\
implantation deaths & $2.91 \pm 0.76^{\mathrm{a}}$ & $4.71 \pm 1.58$ & $4.85 \pm 1.51$ & $4.96 \pm 1.15$ & $5.65 \pm 1.28$ & $10.66 \pm 3.34^{\mathrm{a}}$ & $8.71 \pm 1.43^{\mathrm{a}}$ \\
Post-implantation mortality, \% & $47.35 \pm 1.18^{\mathrm{a}}$ & $43.50 \pm 1.79$ & $40.73 \pm 1.40^{\mathrm{a}}$ & $39.14 \pm 2.68^{\mathrm{a}}$ & $40.94 \pm 3.29$ & $42.70 \pm 2.45$ & $37.94 \pm 2.71^{\mathrm{a}}$ \\
Litter weight, g & $4.11 \pm 0.07^{\mathrm{a}}$ & $4.12 \pm 0.05$ & $4.00 \pm 0.13$ & $4.01 \pm 0.09$ & $3.81 \pm 0.08^{\mathrm{a}}$ & $3.89 \pm 0.10$ & $3.94 \pm 0.11$ \\
Fetal weight, g & & & & & & &
\end{tabular}

Notes: no significant differences between the groups were found according to the parameters; differences between the parameters of control and experimental groups are indicated by the letter $-\mathrm{a}(\mathrm{P}<0.05)$, according to the Tukey test.

The maximal and middle doses of AC1 had a noticeable negative effect on reproductive capacity of male animals as evidenced by the parameters of reproductive function of intact females that became pregnant by mating with them. The number of live fetuses in the treated group, where animals received the maximum dose, decreased significantly (14.9\%), while the number of embryo and fetal deaths after implantation and the percentage of post-implantation mortality increased $(171.4 \%$ and $199.3 \%$, respectively), as compared to the control group. In the treated group, where animals received $\mathrm{ACl}$ at a dose of $1.0 \mathrm{mg} / \mathrm{kg}$, absolute and relative mortality after implantation increased $(233.3 \%$ and $266.3 \%$, respectively, above control). In the experiment with $\mathrm{ACl}$ in all treated groups, the average weight of fetuses' decreased in relation to the control values, reaching 
statistical significance in the group of males receiving the minimal dose $(\mathrm{P}<0.01)$. The same tendency was observed when determining the average litter weight that decreased significantly ( $19.9 \%$ below control) when animals were exposed to the maximum dose.

During a two-week period of monitoring the estrous cycle in females exposed the middle and minimal doses of the test substance, there were no significant deviations in the frequency and length of the estrous cycle and each of its stages. Only in animals exposed to the maximum dose of ACl was there observed a significant increase in the length of the estrogendependent stage, proestrous, by $38.3 \%$ as compared to the control group $(0.83 \pm 0.04$ and $0.60 \pm 0.04$, respectively, $\mathrm{P}<0.001)$.

The values of the index of fertility in the groups where animals received the middle and minimal doses of $\mathrm{ACl}$ decreased slightly but not statistically significantly. As in case of male animals, ACl had a negative effect on fertility of female animals. When exposed to the middle and maximum doses a significant decrease of the number of corpora lutea (9.3\% and $10.3 \%$, respectively, below control) and live fetuses $(10.7 \%$ and $14.0 \%$, respectively, below control) was observed. The average litter weight in females of these groups decreased significantly $(14.0 \%$ and $17.3 \%$ ) as compared to that parameter in control females.

Thus, according to our study, exposure of male and female Wistar Han rats to alpha-cypermethrin at doses of $0.2-3.0 \mathrm{mg} / \mathrm{kg}$ during gametogenesis had a toxic effect on the reproductive system characterized by impaired gonadal and reproductive functions. At the same time, there were no signs of systemic toxic effect, i.e., alpha-cypermethrin demonstrated selective toxicity to reproductive function. Males were found to be more sensitive to the endocrine-disrupting effect of the studied agent as compared to females. Obvious signs of endocrine reproductive disorders were observed in both females and males (changes in testis and epididymis weight, deterioration in semen parameters, altered length of separate stages of the estrous cycle).

And since pathological changes of an endocrine nature ultimately affect the processes of spermatogenesis and oogenesis, this leads to a disruption of the fertilizing function of spermatozoa in males and to a disruption of the ability to conceive in females, and is also accompanied by a reduced viability of embryos and fetuses at the stages of pre- and post-implantation periods of development. In the experiment with AC1, the NOAEL was not determined (decrease in fetal weight after exposure of male animals to a dose of $0.2 \mathrm{mg} / \mathrm{kg})$.

\section{Discussion}

The endocrine-disrupting potential of cypermethrin and alpha-cypermethrin has been confirmed by numerous literature data indicating estrogen-like and anti-androgen effects of these compounds when studied in vitro, although the mechanisms of endocrine-mediated disorders are still unclear (Kozak et al., 2020). Thus, Saito et al. (2000) assessed the possible estrogenic and antiestrogenic activity of cypermethrin using three in vitro assays (cell luciferase reporter gene, yeast two-hybrid assay, and ligand competitive binding assay) with classical ligand-mediated activation mechanisms. The authors concluded that cypermethrin's estrogenic or antiestrogenic activity, when tested in vitro, bypasses the classical pathway mediated by the human estrogen receptor $\alpha(\mathrm{hER} \alpha)$. Sumida et al. (2001) came to a similar conclusion, arguing that cypermethrin does not bind to the human progesterone receptor (hPR) in vitro, and Kim et al. (2004), concluding the absence of estrogenic or antiestrogenic activity of cypermethrin through classical ER-mediated pathways in vitro.

However, Chen et al. (2002) indicate that cypermethrin induces an ER-specific agonist response. In these studies, the estrogenic activity of cypermethrin was also examined using 3 in vitro assays (E-screen assay, estrogen receptor (ER) competitive binding assay, $\mathrm{pS} 2$ expression assay). Cypermethrin significantly induced the proliferation of $\mathrm{MCF}-7$ cells. In addition, the high concentration of cypermethrin inhibited the binding of $(3 \mathrm{H})$ estradiol to the ER and induced the expression of $\mathrm{pS} 2 \mathrm{mRNA}$. The endocrine-disruptive activity of cypermethrin was also demonstrated by the work of Kakko et al. (2004), in which cypermethrin enhanced the proliferative effect of $0.1 \mathrm{nM}$ estradiol when used in low concentrations $(0.1-1.0 \mu \mathrm{M})$ together with estradiol in MCF-7 cells. Cypermethrin can also disrupt the processes of steroidogenesis by modulating the activity of such an essential enzyme as aromatase, which transforms androgens into estrogens. Cypermethrin induced aromatase activity in human choriocarcinoma cells after 24 hours of exposure, starting at a concentration of $3 \mu \mathrm{M}$ (Laville et al., 2006). The work of Sun et al. (2007) shows that not only cypermethrin but also its metabolite 3-PBA have antiandrogenic activity in in vitro studies. Conflicting data on the endocrine-mediated pathways of cypermethrin interaction may be due to the impossibility of identifying and studying the entire cycle of metabolic transformations of the tested agent in in vitro studies. This assumption is supported, particularly by the studies by McCarthy et al. (2006), who showed that some pyrethroid metabolites, in particular permethrin and cypermethrin, have chemical structures that are more likely to interact with the cellular estrogen receptor than the parent pyrethroids. For this study, the metabolites of permethrin and cypermethrin 3-(4-hydroxy-3-phenoxy)benzyl alcohol, 3-(4-hydroxy-3-phenoxy)benzoic acid, and N-3-(phenoxybenzyl)glycine were synthesized. Together with commercially available 3-phenoxybenzyl alcohol, 3-phenoxybenzaldehyde and 3-phenoxybenzoic acid, the synthesized metabolites in a recombinant yeast test expressing human estrogen receptors (YES) were studied. Three metabolites, 3-phenoxybenzyl alcohol, 3-(4-hydroxy-3-phenoxy)benzyl alcohol, and 3-phenoxybenzaldehyde, showed estrogenic activity. According to the authors, the results of this study indicate that pyrethroid metabolites can interact with human estrogen receptors and, therefore, may pose a risk to human health and the well-being of the environment.

Of considerable interest are also works devoted to studying the endocrine-disruptive activity of various stereoisomers of cypermethrin. Zhang et al. (2021) studied the stereoisomeric selectivity of the endocrine-disruptive capacity of $\alpha$-cypermethrin ( $\alpha$-CYP), $\beta$-cypermethrin ( $\beta$-CYP) and $\theta$-cypermethrin $(\theta$-CYP). This study used dual-luciferase reporter gene assays to analyze their potential endocrine disruptive effects through four receptors (estrogen receptor- $\alpha(\mathrm{ER} \alpha)$, glucocorticoid receptor- $\alpha(\mathrm{GR} \alpha)$, mineralocorticoid (MR), and retinoid X-receptor (RXR). The results showed that $\alpha$-CYP is antagonistic to $\mathrm{ER} \alpha, \mathrm{GR} \alpha$ and MR at concentrations (RIC20) of $9.1 \times 10^{-7}, 7.6 \times 10^{-7}$, and $1.0 \times 10^{-6} \mathrm{M}$, respectively. $\beta$-CYP exhibited only ER $\alpha$-mediated agonist activity at a concentration (RIC20) of $2.1 \times 10^{-6} \mathrm{M}$. None of the CYP stereoisomers interacted with RXR. Molecular docking has shown that $\alpha$-CYP has the most potent ability to bind to GR $\alpha$ among the compounds studied. Expression levels of genes associated with steroid hormones in human adrenal cortex carcinoma (H295R) cells showed that all three compounds inhibit the transcription of 3- $\beta \mathrm{HSD}$, indicating a blockage of the conversion of cholesterol into various hormones. Both $\alpha-C Y P$ and $\beta$-CYP activated genes encoding estrogen- and aldosterone-forming enzymes, including $17-\beta H S D$, CYP19, STAR, and CYP11B2. Toxicity analysis for mortality and malformation in zebrafish embryos showed that the order of toxicity is as follows: $\alpha$-CYP $>\beta-$ CYP $>\theta-C Y P$. The authors concluded that $\alpha-C Y P$ could have the most substantial damaging effects on the endocrine system.

Guizhen Du et al. (2010) provided evidence that various pyrethroids and their metabolites can interfere with the function of multiple nuclear hormone receptors and thus potentially affect the endocrine and reproductive systems in humans. In their studies, the authors evaluated and compared the activity of nine pyrethroids (cycloprotrin, cyfluthrin, cyhalothrin, cypermethrin, deltamethrin, etofenprox, fenvalerate, permethrin and tetramethrin) and their metabolites (3-(2,2-dichlorovinyl)-2,2-dimethylcyclopropenecarboxylic acid (DCCA) and 3-phenoxybenzoic acid (3-PBA)) by acting on three hormone receptors (estrogen receptor (ER), androgen receptor (AR), and thyroid hormone receptor (TR)) using luciferase receptor-mediated reporter gene assays. Of the 11 compounds tested, four (cyhalothrin, deltamethrin, fenvalerate, permethrin) showed feeble agonist activity to ER and six (cycloprotrin, cyfluthrin, etofenprox, permethrin, 3-PBA, DCCA) showed antiestrogenic effects, among which cyhalothrin and DCCA had the most potent estrogenic and antiestrogenic activity, respectively. AR antagonistic effects were found in 7 compounds (cyfluthrin, cyhalothrin, cypermethrin, deltamethrin, fenvalerate, permethrin, 3-PBA); cyfluthrin and deltamethrin exhibited more robust AR antagonistic activities. In the TR test, all chemicals tested except DCCA showed antagonistic effects. These studies further support the antiandrogenic effects of cypermethrin. Taking into account that thyroid hormones are a critical regulator of the development, metabolism and homeostasis of vertebrates, 
the destructive effects of the thyroid endocrine chain caused by pyrethroids may be one of the factors inducing reproductive pathology in our experiments.

Far less in vivo research on the whole organism has done; however, in these studies, reproductive toxicity and endocrine-disrupting effect of these compounds are beyond doubt.

The contribution of decreased androgen receptor (AR) expression to cypermethrin-induced reproductive disorders was investigated by $\mathrm{Hu}$ et al. (2013). In this experiment, five groups of adult male Sprague-Dawley rats received various doses of cypermethrin $(0,6.25,12.5,25$ and $50 \mathrm{mg} / \mathrm{kg}$ per day) by intragastric gavage for 15 days. At the end of the exposure period, the testes, epididymis, seminal vesicles, and prostate were removed and weighed. One testis to be used for daily sperm production was frozen. The other testis for AR immunohistochemistry and electron microscopic observation was processed. It was found that prostate weight significantly reduced when exposed to cypermethrin at doses of 25 and $50 \mathrm{mg} / \mathrm{kg}$ per day. Rats treated with cypermethrin at a dose of $50 \mathrm{mg} / \mathrm{kg}$ per day showed a significant decrease in daily testicular sperm production. In the seminiferous tubules, changes, including atrophy and deformation of the seminiferous tubules, reduction and deformation of spermatogonia, spermatocytes, and dislocation of spermatoblasts, were noted. Ultrastructural changes in the cypermethrin-treated groups with impaired intercellular connections, abnormal nuclear morphology, and necrosis of spermatocytes, spermatogonia and Sertoli cells were found. AR expression and serum testosterone levels were analyzed to clarify the possible mechanism of the identified effects. AR expression levels in rats receiving all doses of cypermethrin were significantly reduced, and serum testosterone levels in rats receiving cypermethrin at $50 \mathrm{mg} / \mathrm{kg}$ per day were decreased. According to the authors, these data indicate that cypermethrin can cause a violation in the structure of seminiferous tubules and spermatogenesis in male rats due to a decrease in AR expression.

Sharma et al. (2014) studied the effect of cypermethrin on the male gonads in a short-term experiment. They showed a significant damaging impact on the function and morphology of the testes and their epididymis. For 14 days, rats were exposed to cypermethrin $(3.83 \mathrm{mg} / \mathrm{kg}$ body weight). At the end of the experiment, the testes and epididymis were removed and characteristics of spermatozoa, sex hormones, and various biochemical parameters in rats were studied.

Exposure to cypermethrin resulted in significant reductions in testicular and epididymal weight, testicular head count, motility and live sperm count, and increased sperm abnormalities. Serum testosterone (T), folliclestimulating hormone (FSH), luteinizing hormone ( $\mathrm{LH})$, reduced glutathione (GSH), catalase (CAT), superoxide dismutase (SOD), glutathione S-transferase (GST), glutathione reductase (GR) content (GPx) and total protein (TP) were decreased, and lipid peroxidation (LPO) level was increased on cypermethrin exposure.

Cypermethrin is also toxic to the reproductive system of male guinea pigs. In a study by Vemo et al. (2018), four groups of adult male guinea pigs (10 animals each) were orally administered cypermethrin at doses of $0,92,137.5$ and $275 \mathrm{mg} / \mathrm{kg}$ bw/day for 90 days. Before they were killed, at the end of exposure, the animal's libido (time of the male's reaction to the presence of a female) was studied. After the animals were killed, the weight and volume of testes, epididymis, vas deferens, vesicular glands, prostate, liver and kidneys were recorded. Sperm parameters, testosterone concentration and biochemical parameters were determined. As a result of exposure, the weight of the liver increased significantly, while the weight of the kidneys significantly decreased in animals treated with cypermethrin compared with the control. Serum concentrations of creatinine, urea, aspartate aminotransferase (ASAT), alanine aminotransferase (ALAT), total cholesterol, and prostate acid phosphatase increased significantly. In contrast, total testicular protein levels significantly decreased in the insecticide-treated groups compared to controls. Testicular weight, libido, serum testosterone, motility, sperm count, and percentage of whole plasma membrane sperm were significantly reduced in cypermethrin-exposed animals compared to controls. The percentage of abnormal spermatozoa in animals treated with cypermethrin at 137.5 and $275 \mathrm{mg} / \mathrm{kg}$ body weight increased significantly compared with control animals. On histological sections of the testes of animals exposed to the pesticide, immature germ cells in the lumen of the seminiferous tubules were observed.
To elucidate some aspects of the mechanism of the toxic effect cypermethrin on the reproductive system, detection markers of apoptosis (Caspase3, p53 and Bcl-2) in the tissues of the testes and the brain and determination of follicle-stimulating hormone (FSH), luteinizing hormone (LH) and testosterone in serum were made (Abd El-Hameed \& Mahmoud, 2020). In animals that received the test substance at a dose of $3 \mathrm{~mL} / \mathrm{kg}$ bw/day for 60 days, the biochemical analysis showed a decrease in serum levels of testosterone, hormones LH and FSH, an increase in the expression of caspase 3 and p53 in the brain and testes, as well as a decrease in expression of Bcl-2. Based on the studies carried out, the authors concluded that biochemical changes in apoptosis caused by cypermethrin in the tissues of the brain and rats testes contribute to the impairment of reproductive parameters.

As for the study of reproductive toxicity in three generations, one should note that the experiments with cypermethrin, which is a racemic mixture of cis and trans isomers, were carried out, but the results of studies on three generations apply to alpha-cypermethrin, a racemic mixture containing only cis- isomers since the toxicity of alpha-cypermethrin was found to be equivalent to that of cypermethrin.

Reproductive toxicity studies of cypermethrin in a 3-generation test system were carried out twice. In 1978-1979 the first experiment in the Shell Toxicology Laboratory was carried out (Hend et al., 1979). Groups of animals containing 30 Wistar rats of each sex for three generations $\left(\mathrm{F}_{0}\right.$, $\mathrm{F}_{1}, \mathrm{~F}_{2}, 2$ litters/generation) were continuously exposed to cypermethrin (98\% purity) when fed with food at concentrations of $0,10,100$ and $500 \mathrm{ppm}(0.1,10,50 \mathrm{mg} / \mathrm{kg}$ body weight $) . \mathrm{F}_{0}$ adults were exposed for five weeks before mating to produce $F_{1 a}$ litters. Litter $F_{1 b}$ was obtained by mating $\mathrm{F}_{0}$ animals of parental generations 5 weeks after weaning of the first litter. $F_{1 b}$ rats were exposed for at least 10 weeks before mating and for two gestation and weaning cycles to produce litters $F_{2 a}$ and $F_{2 b}$. Generation $F_{2 b}$ was exposed similarly to $F_{1 b}$ pups to produce litters $F_{3 a}$ and $F_{3 b}$. In this experiment, at a concentration of $500 \mathrm{ppm}$, cypermethrin induced a decrease in body weight gain and food consumption in animals of both sexes of all generations. NOEL $=100 \mathrm{ppm}$. According to the conclusions of the authors of the studies, there were no other effects associated with the exposure of the animals to the test compound, their reproductive ability or on pups. There were no side effects.

In accordance with a conclusion of California EPA Department of Pesticide Regulation the study was deemed unacceptable and could not be updated because there was no analytical data for the test material. In addition, there was no description of the method used to analyze the feed, and there was no justification for the doses used. The autopsy and histopathological data were found to be inadequate, and some data were lacking on the animals of the parental generations.

The second study in the ICI Central Toxicology Laboratory, Alderley Park, UK, in 1982 was conducted. Four groups of animals, each containing 15 male and 30 female Wistar rats, continuously consumed food containing cypermethrin $(91.5 \%, 93.1 \%, 90.6 \%$ purity) at concentrations of $0,50,150$ and $750 \mathrm{ppm}$ for three generations $\left(\mathrm{F}_{0}, \mathrm{~F}_{1}, \mathrm{~F}_{2}\right)$ with 2 litters per generation $\left(\mathrm{F}_{1 \mathrm{a}}, \mathrm{F}_{1 \mathrm{~b}}, \mathrm{~F}_{2 \mathrm{a}}, \mathrm{F}_{2 \mathrm{~b}}, \mathrm{~F}_{3 \mathrm{a}}, \mathrm{F}_{3 \mathrm{~b}}\right)$. Animals of the $\mathrm{F}_{0}$ generation received 1000 ppm for the first 12 weeks, after which the concentration of the test compound was reduced to $750 \mathrm{ppm}$, as the initial maximum dose caused neurological effects between 3 and 22 days in most animals of both sexes of the parental $F_{0}$ generation and the death of one male on day 9 . Ten days after weaning of $F_{1 a}$ rat pups, the $F_{0}$ generation adult animals crossed again to produce $F_{1 b}$ litter. Selected $F_{1 b}$ weaners were exposed for 11 weeks and then bred similarly to $F_{0}$ offspring to produce $F_{2 a}$ and $F_{2 b}$ litters. This cycle with selected $F_{2 b}$ weaners to produce $F_{3 a}$ and $F_{3 b}$ litters was repeated.

In adult $\mathrm{F}_{0}$ generations of both sexes, body weight gain decreased when exposed to $1000 \mathrm{ppm}$ and in females fed food with $150 \mathrm{ppm}$ cypermethrin, $F_{1}$ females when exposed to $750 \mathrm{ppm}$, and in $\mathrm{F}_{2}$ males and females when exposed to 150 and 750 ppm were observed. These animals also had decreased food intake. The results obtained indicate the systemic toxicity of cypermethrin at concentrations of 150, 750 and $1000 \mathrm{ppm}$. No effect of cypermethrin on reproductive parameters was observed. According to the conclusion of the researchers, NOEL for parental generations $=50 \mathrm{ppm}$. Concentrations of 750 and $1000 \mathrm{ppm}$ had a systemic toxic effect on the offspring, manifested by decreased weight and weight 
gain in newborns and rat pups during lactation. The lactation index also decreased. NOEL for development in this experiment, according to the study authors' conclusion, $=150 \mathrm{ppm}$. This study, in accordance with a conclusion of California EPA Department of Pesticide Regulation was deemed acceptable.

In conclusion, we would like to note that pesticides are one of the most common pollutants of anthropogenic origin in the environment. Nevertheless, their use continues to grow, since until now, humanity has not found an adequate replacement for chemical plant protection products. Synthetic pyrethroids are not the last place in the range of pesticide preparations which have high insecticidal activity and relatively low consumption rates. At the same time, the majority of pesticide preparations, applied for their intended purpose, destroying the vital functions of agricultural pests, cannot be harmless when exposed to non-target organisms. And as can be seen from the data presented, pyrethroids have endocrine-disruptive properties when the mammalian body is exposed to them, causing disturbances in various organs and systems, including the reproductive system (Perry et al., 2007; Jin et al., 2010; Zhao et al., 2010). The endocrine-disruptive properties of pyrethroids are associated with a dysfunction of many nuclear and hormonal membrane receptors, which ultimately leads to pathological changes in the function of the gonads and the reproduction processes of offspring (Du et al., 2010; Kim et al., 2015; Das et al., 2017).

Our results entirely correlate with the data of several studies, which showed that the stages of gametogenesis and early fetal development are the most vulnerable of the reproductive process to the action of endocrine disruptors (Sultan et al., 2001; Skakkebaek et al., 2002; Hardell et al., 2011; Mnif et al., 2011). As shown earlier (Shepelskaya \& Kolianchuk, 2018), when studying the reproductive toxicity of 156 samples of twenty pesticides (Table 1), endocrine-disruptive properties of all tested compounds in the test system of gonadotoxic activity were found. The presence of endocrine-disruptive potential in the pesticides studied by us, and the close relationship between hormonal changes and disorders of spermatoand oogenesis, identified in our studies, is also confirmed by the literature data presented in the article. At the same time, results of a comparative analytical evaluation of these substances in test systems of the 2nd and 3rd generations showed that only two drugs out of 20 have these properties.

\section{Conclusions}

The selective and, therefore, the most dangerous effects of pesticides on the reproductive system were determined for the endocrine-disupting properties of the agents under study. Most of pathological changes in reproductive function in the case of exposure to endocrine disnuptors (disnuption of sexual behaviour, decreased indices of conception and fertilization, decreased fertility, deterioration in semen parameters up to azoospermia, decreased viability of fertilized eggs, increased intrauterine deaths of embryos and fetuses of $F_{1}$ generation) were caused by the influence of toxic compounds during the pre-embryonic stage of gametogenesis. The test system for studying the gonadotoxicity of pesticides meets the main requirements that ensure the reliability and objectivity of any research methodology; these are, first of all, information content, high sensitivity and resolution, scientific validity of approaches, and diagnostic value. The advantages of the test system for studying gonadotoxic activity should also include the ability to identify the effect of the test compound on the target organ and its sexual selectivity, as well as, which is important, relatively high economic efficiency. Sensitivity, informative and diagnostic values of the methods for studying gonadotoxicity greatly exceeded those of three-generation reproduction studies.

This work was carried out within the framework of the government research project "Scientific substantiation of modern regulatory requirements for the use of pesticides and agrochemicals: predicting long-term effects of action (carcinogenic, mutagenic, teratogenic activity, reproductive toxicity, chronic intoxication)", state registration No. $0108 \mathrm{U} 007458$.

\section{References}

Abd El-Hameed, A. M., \& Mahmoud, H. S. (2020). Cypermethrin induced apoptosis and testicular toxicity by upregulation of $\mathrm{p} 53$ in the brain and testis of male rats is alleviated by Sesame oil. Journal of Taibah University for Science, 14(1), 1342-1349.

Barnes, J. M., \& Denz, F. A. (1954). Experimental methods used in determining chronic toxicity: A critical review. Pharmacological Reviews, 6(2), 191-242.

Brehman, I. I. (1990). Valeologija - nauka o zdorov'e [Valeology is the science of health]. 2nd ed. Physical Education and Sports, Russia (in Russian).

Bretveld, R. W., Thomas, C. M., Scheepers, P. T., Zielhuis, G. A., \& Roeleveld, N. (2006). Pesticide exposure: The hormonal function of the female reproductive system disrupted? Reproductive Biology and Endocrinology, 4(1), 30.

Chen, H., Xiao, J., Hu, G., Zhou, J., Xiao, H., \& Wang, X. (2002). Estrogenicity of organophosphorus and pyrethroid pesticides. Journal of Toxicology and Environmental Health, Part A, 65(19), 1419-1435.

Das T., Ghosh R., \& Paramanik A. (2017). Dose-dependent hematological, hepatic and gonadal toxicity of cypermethrin in Wistar rats. Toxicology and Forensic Medicine Open Journal, 2(2), 74-83.

Delahunt, C. S., \& Lassen, L. J. (1964). Thalidomide syndrome in monkeys. Science, 146(3649), 1300-1305.

Du, G., Shen, O., Sun, H., Fei, J., Lu, C., Song, L., Xia, Y., Wang, S., \& Wang, X. (2010). Assessing hormone receptor activities of pyrethroid insecticides and their metabolites in reporter gene assays. Toxicological Sciences, 116(1), 58-66.

Fishbein, F. (1970). Food and drug administration advisory committee on protocols for safety evaluations: Panel on reproduction: Report on reproduction studies in the safety evaluation of food additives and pesticide residues. Toxicology and Applied Pharmacology, 16, 264-296.

Fitzhugh, O. G. (1968). Reproduction tests. In: Boyland, E., \& Goulding, R. R. (Eds.). Modem trends in toxicology. Butterworth, London. Vol. 1. Pp. 75-85.

Goldman, J. M., Murr, A. S., \& Cooper, R. L. (2007). The rodent estrous cycle: Characterization of vaginal cytology and its utility in toxicological studies. Birth Defects Research. Part B, Developmental and Reproductive Toxicology, 80(2), 8497.

Hardell, L., Bavel, B., Lindström, G., Eriksson, M., \& Carlberg, M. (2006). In utero exposure to persistent organic pollutants in relation to testicular cancer risk. International Journal of Andrology, 29(1), 228-234.

Hend, R. W., Hendy, R., \& Flemming, D. J. (1979). Toxicity studies on the insecticide WL 43467: A three generation reproduction study in rats. Shell Toxicology Laboratory, Tunstall, 2-79.

Hu, J. X., Li, Y. F., Li, J., Pan, C., He, Z., Dong, H. Y., \& Xu, L. C. (2013). Toxic effects of cypermethrin on the male reproductive system: With emphasis on the androgen receptor. Journal of Applied Toxicology, 33(7), 576-585.

Jin, M., Li, L., Xu, C., Wen, Y., \& Zhao, M. (2010). Estrogenic activities of two synthetic pyrethroids and their metabolites. Journal of Environmental Sciences, 22(2), 290-296.

Kakko, I., Toimela, T., \& Tähti, H. (2004). Oestradiol potentiates the effects of certain pyrethroid compounds in the MCF7 human breast carcinoma cell line. Alternatives to Laboratory Animals, 32(4), 383-390.

Kilkenny, C., Browne, W. J., Cuthill, I. C., Emerson, M., \& Altman, D. G. (2010). Improving bioscience research reporting: The ARRIVE guidelines for reporting animal research. PLoS Biology, 8(6), e1000412.

Kim, C. W., Go, R. E., \& Choi, K. C. (2015). Treatment of BG-1 ovarian cancer cells expressing estrogen receptors with lambda-cyhalothrin and cypermethrin caused a partial estrogenicity via an estrogen receptor-dependent pathway. Toxicological Research, 31(4), 331-337.

Kim, I. Y., Shin, J. H., Kim, H. S., Lee, S. J., Kang, I. H., Kim, T. S., Moon, H. J., Choi, K. S., Moon, A., \& Han, S. Y. (2004). Assessing estrogenic activity of pyrethroid insecticides using in vitro combination assays. The Journal of Reproduction and Development, 50(2), 245-255.

Kozak, V. M., Romanenko, E. R., \& Brygadyrenko, V. V. (2020). Influence of herbicides, insecticides and fungicides on food consumption and body weight of Rossiulus kessleri (Diplopoda, Julidae). Biosystems Diversity, 28(3), 272-280.

Laville, N., Balaguer, P., Brion, F., Hinfray, N., Casellas, C., Porcher, J. M., \& AïtAissa, S. (2006). Modulation of aromatase activity and mRNA by various selected pesticides in the human choriocarcinoma JEG-3 cell line. Toxicology, 228(1), $98-108$

Lehman, A. J. (1959). Appraisal of the safety of chemicals in foods, drugs and cosmetics. Association of Food and Drug Officials of the United States, Topeka.

Lenz, W. (1964). Chemicals and malformations in man. In: Second International Conference on Congenital Malformations. International Medical Congress, New York. Pp. 263-276.

McCarthy, A. R., Thomson, B. M., Shaw, I. C., \& Abell, A. D. (2006). Estrogenicity of pyrethroid insecticide metabolites. Journal of Environmental Monitoring, 8(1), 197-202.

Mel'nikov, N. N., Novozhilov, K. V., \& Belan, S. R. (1995). Pesticidy i reguljatory rosta rastenij [Pesticides and plant growth regulators]. Chemistry, Moscow (in Russian).

Mnif, W., Hassine, A. I., Bouaziz, A., Bartegi, A., Thomas, O., \& Roig, B. (2011) Effect of endocrine distuptor pesticides: A review. International Journal of Environmental Research and Public Health, 8(6), 2265-2303. 
Palmer, A. K. (1978). The design of subprimate animal studies. In: Research Procedures and Data Analysis. Springer, Boston. Pp. 215-253.

Palmer, A. K. (1981). Regulatory requirements for reproductive toxicology: Theory and practice. In: Kimmel, C. A., \& Buelke-Sam, J. (Eds.). Developmental toxicology. Raven Press, New York. Pp. 259-287.

Perry, M. J., Venners, S. A., Barr, D. B., \& Xu, X. (2007). Environmental pyrethroid and organophosphorus insecticide exposures and sperm concentration. Reproductive Toxicology, 23(1), 113-118.

Saito, K., Tomigahara, Y., Ohe, N., Isobe, N., Nakatsuka, I., \& Kaneko, H. (2000). Lack of significant estrogenic or antiestrogenic activity of pyrethroid insecticides in three in vitro assays based on classic estrogen receptor $\alpha$-mediated mechanisms. Toxicological Sciences, 57(1), 54-60.

Seed, J., Chapin, R. E., Clegg, E. D., Dostal, L. A., Foote, R. H., Hurtt, M. E., \& Wise, L. D. (1996). Methods for assessing sperm motility, morphology, and counts in the rat, rabbit, and dog: A consensus report. Reproductive Toxicology, 10(3), 237-244.

Sharma, P., Huq, A. U., \& Singh, R. (2014). Cypermethrin-induced reproductive toxicity in the rat is prevented by resveratrol. Journal of Human Reproductive Sciences, 7(2), 99.

Shepelskaya, N. R., \& Kolianchuk, Y. V. (2018). Comparative analysis of different methodological approaches to the reproductive toxicity hazard identification of pesticides. Bulletin of Problems Biology and Medicine, 145(3), 238-246.

Skakkebaek, N. E. (2002). Endocrine disrupters and testicular dysgenesis syndrome. Hormone Research, 57(2), 43.
Sultan, C., Balaguer, P., Terouanne, B., Georget, V., Paris, F., Jeandel, C., Lumbroso, S., \& Nicolas, J. (2001). Environmental xenoestrogens, antiandrogens and disorders of male sexual differentiation. Molecular and Cellular Endocrinology, 178, 99-105.

Sumida, K., Saito, K., Ooe, N., Isobe, N., Kaneko, H., \& Nakatsuka, I. (2001). Evaluation of in vitro methods for detecting the effects of various chemicals on the human progesterone receptor, with a focus on pyrethroid insecticides. Toxicology Letters, 118(3), 147-155.

Sun, H., Xu, X. L., Xu, L. C., Song, L., Hong, X., Chen, J. F., \& Wang, X. R. (2007). Antiandrogenic activity of pyrethroid pesticides and their metabolite in reporter gene assay. Chemosphere, 66(3), 474479.

Vemo, B. N., Kenfack, A., Ngoula, F., Nantia, E. A., Ngaleu, C. C. N., Guiekep, A. J. N., Tsambou, A. M. M., Yidjeu, F. N., Nelo, C. P., \& Teguia, A. (2018). Toxicity and reproductive parameters impairment of cypermethrin in male guinea pig (Cavia porcellus). Turkish Journal of Agriculture - Food Science and Technology, 6(2), 130-135.

Zhang, Q., Yu, S., Chen, X., Fu, L., Dai, W., \& Gu, S. (2021). Stereoisomeric selectivity in the endocrine-disrupting potential of cypermethrin using in vitro, in vivo, and in silico assays. Journal of Hazardous Materials, 414, 125-389.

Zhao, M., Chen, F., Wang, C., Zhang, Q., Gan, J., \& Liu, W. (2010). Integrative assessment of enantioselectivity in endocrine disruption and immunotoxicity of synthetic pyrethroids. Environmental Pollution, 158(5), 1968-1973. 